\title{
Practice What We Teach: Our Ethical Connection to P-12 Schools
}

\author{
Delores B. Lindsey, Ph.D., \\ Associate Professor, College of Education, California State University, San Marcos \\ Richard S. Martinez, Ed.D. \\ Associate Professor, Azusa Pacific University \\ Randall B. Lindsey, Ph.D. \\ Professor Emeritus, California State University, Los Angeles
}

This article addresses the ethical interface of Educational Administration faculty, our degree and credential candidates, and the educational achievement of pre-school, kindergarten through high school (P-12) students. Culturally Proficient Coaching is presented as a set of integrated tools that can be used by Educational Administration faculty, P-12 school leaders, and classroom teachers in providing for the educational needs of students in our diverse communities.

Today's pre-school, kindergarten-12th grade (P-12) school leaders are expected to have experience and a knowledge base that effectively prepares candidates as instructional leaders in a variety of public schools and school districts (California Commission on Teacher Credentialing, Category I, Standard 1: Program Rationale and Design, p. 37). These expectations are inherent in the California Professional Standards for Educational Leaders (CPSELs), the Standards of Quality and Effectiveness for Preliminary Administrative Services Credential and its predecessor, the Interstate School Leaders Licensure Consortium (IISLC) .The assumptions inherent in this standards-based approach to instructional leadership are that leadership skills and dispositions are developed and strengthened over time and that school leaders know and understand standards-based instruction.

The purpose of standards-based leadership preparation programs and courses is to prepare emerging school leaders and administrators in ways that support instructional environments to ensure all demographic groups of students are achieving at levels higher than ever before (CCTC, 2004; NCLB, 2001). It is important to note that issues related to demography and diversity are considered a contextual issue for each of the CPSELs. This is a remarkable departure from past practice and now values our schools as cultural entities where children and youth from diverse backgrounds can expect their academic and related social needs to be met.

This paper offers a conceptual framework and instructional tools for Educational Administration faculty as we prepare candidates in our programs to be instructional leaders in diverse and complex P-12 educational environments. Cognitive Coaching (Costa \& Garmston, 2002) and Cultural Proficiency (Lindsey, Martinez \& Lindsey, 2007) are two distinct conceptual constructs that offer tools and dispositions for instructional leaders to use in their day-to-day engagements with teachers and staff members. We present coaching and cultural proficiency as integrated sets of tools for guiding individuals and groups to use cross-cultural issues as opportunities and assets rather than as challenges and deficits. This article is written for Educational Administration faculty who want to know how to ask questions that shift thinking in a way that connects our practice and our conversations to P-12 student achievement. Table 1 displays the relationship that Educational Administration faculty might have with P-12 environments when coaching is viewed as indispensable knowledge, skills, and dispositions for faculty, leaders, and teachers.

We encourage Educational Administration faculty to consider the use of coaching skills as an instructional tool and to present coaching as part of the knowledge base and skill development for administrative candidates. This approach is closely aligned with California's leadership standards as detailed in the CCTC program standards document in Standards 6: Opportunity to Learn Instructional Leadership (p. 44):

"The role of the instructional leader is central to the functioning of an effective school, and thus the program provides multiple, systematic 
Table 1

Number and Percentage Distribution of City Public Elementary and Secondary Students, by Race/Ethnicity : $2003-04$

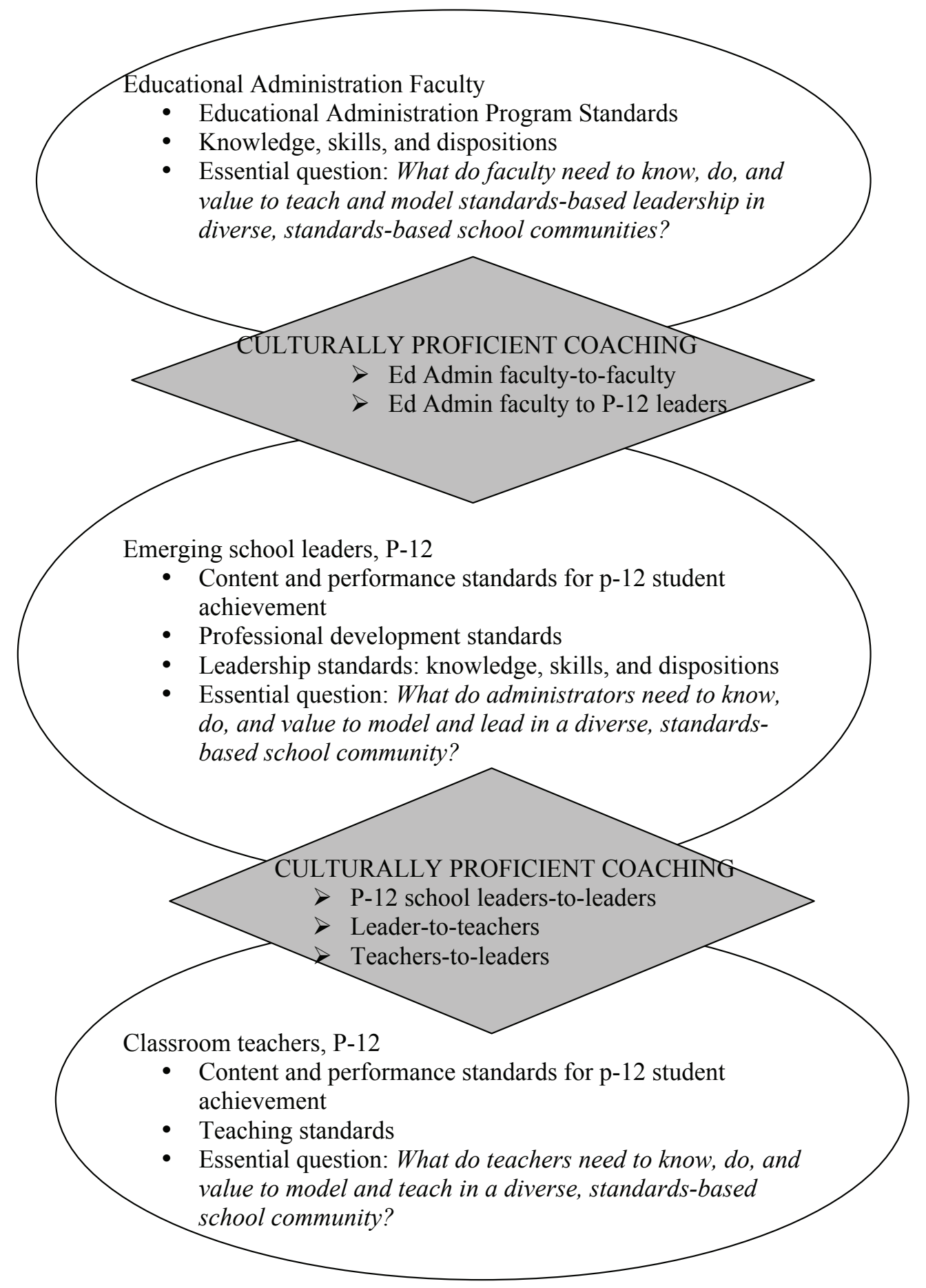


opportunities for the candidate to connect theory to practice and develop the knowledge, skill and disposition to foster effective teaching in the service of student achievement."

The authors of this article believe that these opportunities to learn are enhanced by the faculty member's knowledge of and high value for coaching as an instructional tool to mediate and inform candidates' awareness of their critical roles for articulating a shared vision of teaching and learning in diverse school communities. We propose that Culturally Proficient Coaching is one way for candidates to learn, practice, and reflect on their role as instructional leader.

Culturally Proficient Coaching is based on a set of assumptions derived from our work with P-12 that schools that we believe to be germane to our role as Educational Administration faculty:

- As Educational Leadership faculty, we are in good position to serve as coaches to our degree and credential candidates.

- Our programs can be delivered in such a way as to teach our degree and credential candidates the skills of coaching to use in their everyday leadership roles.

- We know and understand that P-12 schools ARE the context for our work as Educational Administration faculty.

- We demonstrate a commitment to the moral imperative of a P-12 education system that meets the academic needs of all students.

- We hold collaborative learning to be an effective way to improve educational practice.

- Effective leaders can shift the focus of professional conversations from 'the blame game' to focusing on improving one's own practice.

- We can intentionally design and structure 'talk time' in P-12 schools.

- The Mental Model for Culturally Proficient Coaching represents a world view where all children have the capacity to learn at high levels.

\section{Educational Administration Faculty as Coaches}

Coaching is a word that conjures a variety of experiences and metaphors for each reader. Often, we recall our favorite sports coach, or our voice coach, or our spiritual coach as a model for effective coaching. The term, however, has taken on new meaning in today's educational environments. It seems that the noun, coach, is better understood when an adjective precedes it. Modifiers help clarify and describe the role(s) of coaches. Often, candidates in our programs come to us having been actively recruited and trained as literacy coaches, academic coaches, mathematics coaches, leadership coaches, and change coaches just to name a few. Why the increased interest in coaching as an instructional tool? How does coaching influence instructional practice and student achievement? These and other questions come to the forefront as educators confront the need to increase student achievement in schools across the nation.

Educational Administration faculty has numerous opportunities to serve as coaches for our degree and credential/certification candidates. Faculty, who skillfully use the tools of paraphrasing, pausing, and inquiry, mediate shifts in thinking with groups of candidates and in one-toone conversations with candidates. The shift in thinking causes our candidates to consider changes in behaviors. The way we structure our questions either mediates, intimidates, or limits thinking for our candidates. For example, consider the impact and influence the following questions might have on our candidates' thinking during a class discussion about allocating resources to support an instructional program:

- What is the reason for having a budget committee?

This question implies there is only one reason for having the committee and limits the candidates thinking to find that one response.

- Why didn't you include teachers on your budget committee?

This question suggests a right answer and forces the candidate to defend her response.

- Who else might the administrators invite to participate in the budget process?

This question opens up thinking so the candidate considers other possibilities for inclusion. A subsequent coaching question might help the candidate think more specifically about an issue if his responses have been broad and general. For example, the faculty member's question might be When you say 'everyone' should be involved in the budget process, who specifically might you include?

Of course, not all questions must be coaching questions. The faculty member must be clear about her intentions for inquiry and choose behaviors appropriate to the lesson and candidates' desired learner outcomes.

\section{P-12 School Leaders as Coaches}

Why Culturally Proficient Coaching, now? Today's school leaders are expected to develop skills based on their knowledge of standards-based instruction in their diverse, complex school communities. Coaching as a leadership skill provides the leader with opportunities to learn how to develop cooperatively and guide the ongoing and long-term professional development of all staff consistent with the ongoing effort to improve the learning of all students [CCTC, $6 \mathrm{~b}(5)]$. Culturally proficient leadership is one way to describe coaching in today's diverse school settings.

Cultural Proficiency provides the coach with a lens and set of tools for work in cross-cultural settings. To guide your reading and study, we use these definitions of coaching and Culturally Proficient Coaching in our work:

- Coaching

Coaching is a way for one person to mediate and 
influence the thinking and behaviors of another person. Influence can be either instructive or reflective.

- Culturally Proficient Coaching

Culturally Proficient Coaching intends for the person being coached to be educationally responsive to diverse populations of students.

- Mediation

Mediation is the skillful use of coaching tools that supports the people being coached to clarify, refine, modify, or shift thinking to be educationally responsive to diverse populations of students.

Perhaps, the need for Culturally Proficient Coaches is best identified in the current social, political, legal, and cultural context for schooling.

\section{P-12 Schools is The Context for our Work as Educational Administration Faculty}

A fundamental assumption that underlies the act of coaching is to assist and support desired change, both within our candidates as they approach their leadership roles and in their work with P-12 colleagues. As an example, it is our experience that when the concept of change is introduced in the context of diverse P-12 environments, very often people become ever more aware of their environment. We hear expressions such as, Have you had success with kids like these? I really believe it is an issue of poverty and we can't control that! Racism is so pernicious that interventions like coaching, as nice as they may be, just hit the surface. It is often of interest to people who utter such pronouncements that we agree. As Educational Administration faculty we are in a position to support our candidates to recognize and respect the social and political dynamics that swirl around us, but not to capitulate to such forces.

Berliner (2005) has performed a great service in helping us understand the negative effects of poverty and that our nation must address issues of systemic poverty and in doing so, issues of school reform will be even better addressed than current school reform efforts. Again, we agree. At the same time, we pay close attention to studies that report demonstrated progress being made in narrowing the gap (Haycock, Jerald \& Huang, 2001; Perie, Moran \& Lutkus, 2005).

Educational Administration faculty are in a unique position for guiding our candidates to acknowledge that they have little control or influence over the 17 hours that students are not on campus, but that they certainly have an opportunity during the 7 hours that students are on campus to greatly influence student learning environments. During the 7 hours that students are on campus, our candidates have great influence and control over decisions about curriculum, instruction, and learning. While P-12 schools cannot mitigate the very real external forces that impinge on our students, our candidates can learn and acknowledge that these forces exist. We can guide our candidates to use their professional associations to press for policy and legislative actions to address the effects of negative external forces. And, most directly, we can guide our candidates in learning that the improvement of our craft as educators is a life-long process. Coaching, specifically Culturally Proficient Coaching as described in this article, is intended to assist P-12 educators who desire to improve their craft; and, in so doing, positively impact student achievement irrespective of social circumstances.

\section{Meeting the Moral Imperative of P-12 Schooling}

Disparities in student achievementhave been highlighted in unprecedented ways since 2001, when school districts throughout the United States were mandated to address achievement disparities based in demographic analyses (NCLB, 2001). Though several states had implemented similar programs prior to 2001, No Child Left Behind (NCLB) has drawn concerted national attention on the disparities of achievement among demographic groups. Throughout the country, many school districts receiving Federal funds for educating students of poverty (e.g., Title I) have used this mandate as an opportunity to examine student achievement data in ways that clearly identify the achievement gaps that exist between students who have been historically wellserved by our schools and those who have been marginalized in many ways.

As Educational Administration faculty, we can use reports such as those from the National Association of Educational Progress and Education Trust to demonstrate that districts across the country are using assessment data to inform decisions about curriculum, instruction, and learning outcomes and are making headway in narrowing the gap (Haycock, Jerald \& Huang, 2001; Perie, Moran \& Lutkus, 2005). In using research in this way we become the arbiters of hope by guiding our students to learn best practices and not to dwell in the fatalistic stories about schools and districts that struggle in closing the achievement gaps. However, we can point out that in many of these stories of failure, educators often blame students for their family and social circumstances. These beliefs are based on negative racial, social, and cultural stereotypes about who learns and at what levels students can achieve.

\section{Building a Case for Collaborative Learning}

Irrespective of numerous state-mandated, standardsaligned programs developed to close the achievement gap, school leaders continue to look for ways to improve instructional strategies, implement curriculum standards, and meet assessment goals for all students. In response to the call for closing the achievement gap, Educational Administration faculty can guide our candidates to learn how P-12 educators are developing professional, collaborative learning communities (Louis, 1996; Schmoker, 1999; Reeves, 2000; DuFour, 2004). These collaborative communities are transforming schools from environments of blame 
to environments of collaboration. These schools view collaborationand communityasnecessaryelements to combat teacher isolation and student blame. Individual teachers may have developed instructional strategies and assessment tools that demonstrate how all students' needs are met, while other individual teachers struggle with those elements. We can guide our candidates to recognize the structures and conditions that are in place to support teachers. Collaborative efforts between teacher and administrators involve making sense of the assessment data, identifying student needs, and implementing strategies to respond to those needs. Through our modeling of examining best practices, our candidates learn that teaching and learning are enhanced by positive interactions between the teacher and their learners.

The literature is clear: learning is a social construct. We can guide our candidates to learn from research to construct environments in which administrators, teachers and students engage in conversations for the clear purpose of constructing knowledge. (Weick, 1995; Wenger, 1998; Wheatley, 2005; and Kana'iaupuni, 2005). For example, often when an Educational Administration instructor engages class members in a conversation about a topic of interest, an issue, an event, a lesson, or even a problem, comments and questions from diverse perspectives and experiences may influence their thoughts and consequent behaviors. Students walk away saying:

"Now, that topic makes more sense to me," or,

"Thanks for helping me sort through that issue," or

"Thanks for listening. I just needed for someone to

listen to me."

Often, everyone in the discussion or conversation benefits in some way from the interaction among the speakers. Learning occurs as a result of conversations, formal or informal, and in structured or unstructured situations. The more intentional or structured the conversation is, the more formal are the learning outcomes. In P-12 school settings educators are starved for time to have structured, meaningful conversations. Through our direct instruction and coaching we can teach and guide our candidates in developing techniques and skills for meaningful conversations that focus on how to serve the educational needs of our diverse student populations.

\section{Shifting Conversations from 'Blame' to 'Our Practice'}

Today's emerging school leaders must be engaged in professional conversations, both formal and informal, focused on how the educational practices of teachers, administrators and counselors impact student achievement. For too long, conversations in educators' lounges and workrooms have been about what the students can't do, won't do, don't know, or don't care about. Educators say, We're just venting, as a way to exonerate themselves from talking about students in an informal, non-professional manner. Now is the time for Educational Administration faculty to guide our candidates as prospective and current $\mathrm{P}-12$ educational leaders to confront colleagues' negative comments about students by asking questions that help surface the long-held assumptions about who can and will learn.

Often, candidates in educational administration courses report that they get up and leave when the conversations of their colleagues are negatively focused on students are underserved. In our educational administration courses, we must challenge these emerging leaders to stay and be willing to say something in support of students and their parents. The culturally proficient leader might ask or state:

- What is it that we might do in our classrooms to address the needs of these students that we have not reached yet?

- What are some other ways that we might reach out to these students in an effort to better determine their needs?

- That is not how l experience these students. My experience has been that when treated in respectful ways and when presented with high expectations and rigorous assignments, the students perform quite well.

Colleagues who ask questions or make statements that are practice-focused help shift the conversation from blaming students to educators' assuming professional and personal responsibility for providing practices that meet the needs of our diverse student bodies.

\section{Intentionally Designing and Structuring 'Talk Time'}

Recently, researchers have identified a positive relationship between professional learning communities and improved student achievement (Raisch, 2005; Greene, 2004; Louis, 1996; Garmston \& Wellman, 2000). Site administrators who are aware of the power and potential of collaborative work time and planned conversations create conditions for teachers to have designated time during the workday to talk, plan, and learn together (Murphy and Lick, 2001; Mahon, 2003; and Wheelan and Kesserling, 2005). Several formal learning community models support teachers and administrators in many of today's comprehensive, systematic school reform projects (e.g., Comprehensive School Reform, Title I, and Reading First). Current formal designs for teacher collaboration include professional learning communities, learning organizations, faculty study groups, and adaptive schools, just to name a few (DuFour, 2005; Garmston \& Wellman, 1999). Table 2 highlights the shift that professional learning communities make when focused on learning and achievement (DuFour, 1998, \& Garmston \& Wellman, 2000).

When attention shifts from a focus on teaching to a focus on student learning and achievement the noticeable shift is accompanied by observable behaviors found to be common in professional learning communities (Louis, 1996; Wenger, 1998; DuFour, 2004; Bloom, 2005).

Table 3 illustrates five behaviors demonstrated in professional learning communities.

In our Educational Administration programs we have the opportunity to help P-12 educators realize that when 
Table 2

Three Primary Strands of Professional Learning Communities that Serve to Shift Instructional Practice

From

Focusing on teaching as presentation

Working independently and in isolation

Measuring teacher success by good intentions

and hard work
To

Focusing on learning and student achievement

Working collaboratively to build shared knowledge

and deeper understanding for addressing

success for each and every student

Assessing effectiveness based

on student achievement results

Table 3

Behaviors Educators Share in Professional Communities

Share norms and values

Collectively focus on student learning

Collaborate about instructional choices

Deprivatize practice

Participate in reflective dialogue 
they open their classroom and office doors to colleagues and coaches they are taking critical steps toward deprivatizing their practice. Teachers working together to improve student achievement often share assessment data, co-create lesson designs, and pool resources and materials of instruction. The question for our P-12 colleagues is no longer Why collaborate?, rather, How do we collaborate?

Educational Administration faculty can guide candidates to learn that structuring time for collaborative learning opportunities is but a first step to improve student achievement. A subsequent step is for our candidates to develop professional skills in marshalling organizational resources (i.e., time, people, money, and materials) to support a positive school climate and organizational cultural. These initial steps are described in the leadership literature as transactional in nature and are often grounded in the assumption that teachers respond to managementby-rewards and sanctions (Hoy \& Miskel, 2005). Subsequent leadership steps that are transformational in nature requires the leader to have knowledge and skills as coaches and mentors to help teachers and other leaders develop t higher levels of performance by taking responsibility their won development (Hoy \& Miskel, 2005). This transformation in thinking leads to actions that allow educators to focus conversations and communications on student progress as the important next step after allocating sufficient time for professional learning. The language of collaboration requires school leaders' awareness of the need for P-12 educators to professionally talk about student achievement, knowledge of skillful ways of talking, and development of a shared set of norms about how to effectively communicate as group members.

Intentional coaching is a way to plan for and develop collaborative learning communities. Planning conversations, using an intentionally designed coaching format, must be focused on student achievement and improvement of instructional practice. In collaborative learning communities teachers focus on intentional conversations and planning sessions about student learning goals, progress of students using selected interventions, parent engagement in student progress, and new instructional strategies based on analysis of student achievement data.

\section{Culturally Proficient Coaching is a Way to View the World}

Culturally Proficient Coaching is a world view, or mental model, for mediating thinking and changes in behaviors for self and others. How one views the world, in part or whole, is a matter of how one is socialized to view the world. Cultural Proficiency embodies a worldview that holds cultural differences as human made and recognizes that cultural differences are often used to justify the enforcement of superior-inferior relationships. Systems of oppression have existed from time immemorial and rather than perpetuate disparities, the culturally proficient educator commits herself to the elimination of human-made barriers to student learning and achievement. By definition, Culturally Proficient Coaching is an intentional, inside-out approach that mediates a person's thinking toward values, beliefs, and behaviors that enable effective cross-cultural interactions to insure an equitable environment for learners, their parents, and all members of the community.

Culturally Proficient Coaches serve as mediators for another's self-directed learning in ways that help reveal, modify, refine, and enrich meaning, decisions, and behaviors that are intentional and supportive of culturally diverse environments. The coach is aware that mediation as described by Costa and Garmston (2002) produces new connections and thoughts in the brain. Often, issues of race, culture, gender identity, and class create a climate of distrust, anger, and guilt among and with teachers and the communities they serve. Brain researchers have demonstrated how thinking often shuts down when a person lives and works in a climate of distrust or hostility. The Culturally Proficient Coach is aware of where the speaker is and helps mediate that person to where the speaker wants to be and behave. Mediating another's shift in thinking from a sense of helplessness and rigidity to an attitude of confidence and flexibility requires the skills of Cognitive Coaching within the frame of diversity and equity. Cultural Proficiency provides that frame of reference for the coach.

Table 4 presents the Mental Model of Culturally Proficient Coaching. The model combines two of the tools of Cultural Proficiency and the Cognitive Coaching framework. The Cultural Proficiency Continuum and the Essential Elements of Cultural Competence are aligned with the Five States of Mind from Cognitive Coaching to provide a framework and standards for developing explicit behaviors and practices that direct our work as educators.

The Mental Model of Culturally Proficient Coaching (MMCPC) is comprised of two axes of information. The horizontal axis presents the six points of the Cultural Proficiency Continuum arranged into two sections:

- Column\#1 represents world views that considers diversity as a problem to be solved. Cultural Destructiveness, Cultural Incapacity, and Cultural Blindness represent behaviors that consider students' culture, their parents/ guardians, the neighborhoods in which they live, and their home language as being problematic.

- Columns \#3 - \#5 represent a worldview that considers culture and diversity of value and serve as the basis for meeting the needs of our children and youth. You will note that as you read from columns 3 to 5 the behaviors grow from awareness, to commitment, to advocacy. Column \#4 represents the Five Essential Elements of Cultural Competence, which serve as the standards for effective cross-cultural educational practice.

- Column \#2 represents the Five States of Mind of Cognitive Coaching. These states of mind serve as educators' 
Table 4

The Mental Model of Culturally Proficient Coaching

\begin{tabular}{|c|c|c|}
\hline FROM: & TO: \\
TOLERANCE FOR & TRANSFORMATION FOR EQUITY \\
DIVERSITY & The focus is on our practice as a coach \\
The focus is on them & & T \\
\hline
\end{tabular}

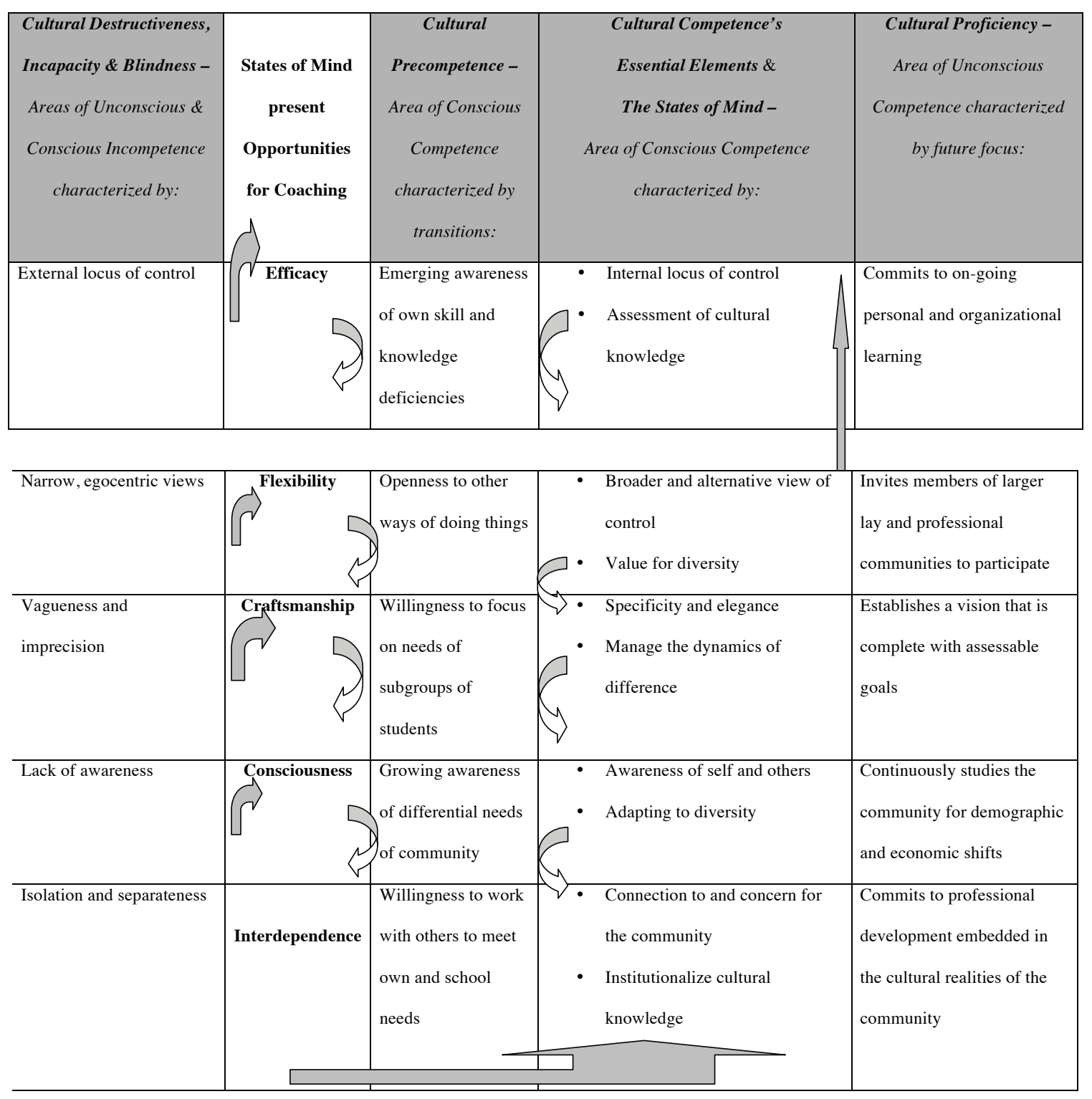


internal resources for mediating thinking and initiating new behaviors.

The vertical axis represents the confluence of the Five States of Mind from Cognitive Coaching and the Five Essential Elements of Cultural Competence. It is these behaviors, skills and dispositions that are designed to meet the needs of our diverse $\mathrm{P}-12$ school constituencies.

\section{Conclusion}

Several usable and useful approaches to educational coaching lend themselves to application in diverse school settings and in Educational Administration Programs (Bloom, Castagna, Moir, and Warren, 2005; Greene, 2004). We offer Culturally Proficient Coaching as a matter of personal preferences and experiences in P-12 schools and their communities. The Tools for Cultural Proficiency described by Lindsey, Nuri Robins, and Terrell (2003) were developed to provide school leaders an inside-out approach to the opportunities and challenges facing schools in today's complex and diverse environments. The tools for Cultural Proficiency can be applied to both organizational policies and practices and individual values and behavior. The tools are used to shift thinking from a tolerance for diversity to a culture of interaction based on respecting and expecting diversity.

In a culturally proficient environment each teacher, administrator, parent, and student has the opportunity to grow as an individual as well as a member of a larger community. The more one knows about one's self, the better prepared the individual is to interact with others in that larger community. Becoming a Culturally Proficient Coach is a personal and professional journey not a destination. As you continue your teaching and learning journey, we ask you to visually hold these questions:

- Who am I in relation to the university in which I teach/ research and the community I serve?

- Who am I in relation to the candidates I teach?

- Who am I in relation to the persons I coach?

- Who am I?

These questions invite, and are designed, to assist ourselves as Educational Administration faculty to challenge ourselves and our candidates to examine our innermost thoughts, beliefs, and assumptions about the communities, the languages spoken, the socio-economics, and the learning styles of the students and parents we serve.

\section{REFERENCES}

Berliner, David. (2005). Our impoverished view of educational reform, Teachers College Record, Date Published: August 02, 2005. http://www.tcrecord.org ID Number: 12106, Date Accessed: August 26, 2005.
Bloom, Gary, Castagna, Claire, Moir, Ellen, \& Warren, Betsy. (2005). Blended coaching: Skills and strategies to support principal development. Thousand Oaks, CA.: Corwin Press.

California Commission on Teacher Credentialing. (2004). Standards of quality and effectiveness for administrative services credentials. Sacramento, CA.: CCTC, January.

Costa, Arthur L., \& Garmston, Robert J. (2002). Cognitive coaching: A foundation for renaissance schools, 2nd ed. Norwood, MA.: Christopher-Gordon Publishers, Inc.

Costa, Arthur L., \& Garmston, Robert J. (2002). Cognitive coaching foundation seminar: Learning guide, 5th ed. Highlands Ranch, Colorado: Center for Cognitive Coaching.

Cross, Terry; Bazron, Barbara, Dennis, Karl, \& Isaacs, Mareasa. (1989). Toward a culturally competent system of care (Vol. 1). Washington, DC: Georgetown

University Child Development Program, Child and Adolescent Service System Program.

DuFour, Richard, \& Eaker, Robert. (1998). Professional learning communities at work:

Best practices for enhancing student achievement. Reston, VA.: Association for Supervision and Curriculum Development.

DuFour, Richard, DuFour, Rebecca, Eaker, Robert, \& Karhanek, G. (2004). Whatever it takes: How professional learning communities respond when kids don't learn. Bloomington, IN.: National Educational Service.

DuFour, Richard, Eaker, Robert, \& DuFour, Rebecca. (2005). On common ground: The power of professional learning communities. Bloomington, IN.: National Educational Service.

Ellison, Jane, \& Hayes, Carolee. (2003). Cognitive coaching: Weaving threads of learning and change into the culture of an organization. Norwood, MA.: Christopher-Gordon Publishers, Inc.

Fullan, Michael. (2003). The moral imperative of school leadership. Thousand Oaks, CA.: Corwin Press.

Garmston, Robert J., \&Wellman, Bruce, M. (1999). The adaptive school: A sourcebook for developing collaborative groups. Norwood, MA.: Christopher-Gordon Publishers, Inc.

Garmston, Robert J., \&Wellman, Bruce, M. (2000). Syllabus - the adaptive school: A sourcebook for developing collaborative groups. El Dorado Hills, CA.: Four Hats Seminars. 
Greene, Terry. (2004). Literature review for school-based staff developers and coaches. Oxford, Ohio: National Staff Development Council.

Haycock, Kati, Jerald, Craig, \& Huang, Sandra. (2001). Closing the gap: Done in a decade. Washington, D.C.: The Education Trust, Inc.

Hoy, Wayne K., \& Miskel, Cecil G. (2004). Educational Administration: Theory, Research and Practice, 7th ed. Boston; McGraw Hill.

Kana'iaupuni, Shawn Malia. (2005). Ka'akalai Ku Kanaka: A call for strengths-based approaches from a native Hawaiian perspective. Educational Researcher, 34(5), 32-38.

Lindsey, Delores B., Martinez, Richard S., \& Lindsey, Randall B. (2007). Culturally proficient coaching: Supporting educators to create equitable schools. Thousand Oaks, CA.: Corwin Press.

Louis, Karen Seashore, Kruse, S.D. \& Marks, H.M. (1996). Teachers' professional communities in restructuring schools. American Educational Research Journal, 33 (4), 757-798.

Mahon, Patrick J. (2003). Professional development for K-12 school reform. Principal Leadership (Middle School Edition), $3(6), 51-3$.

Murphy, Carlene, \& Lick, Dale. (2001). The principal as study group leader. Journal of Staff Development, 22(1), 37-8.

NCLB, No Child Left Behind Act., 2001. http://www.ed.gov/ nclb.

Neufeld, Barbara, \& Roper, Dana. (2003). Coaching: A strategy for developing instructional capacity - promises and practicalities. Queenstown, MD: The Aspen Institute Program on Education, The Annenberg Institute for School Reform.

Perie, Marianne, Moran, Rebecca, \& Lutkus, Anthony D. (2005). NAEP 2004 trends in academic progress: Three decades of student performance in reading and mathematics (NCES 2005-464). U.S. Department of Education, Institute of Education Sciences, National Center for Education Statistics. Washington, D.C.: Government Printing Office.

Raisch, Michele. (2005). Action research aids Albuquerque. National Staff Development Council, 26(3), 50-53.

Reeves, Douglas B. (2000). Accountability in action: A blueprint for learning organizations. Denver, CO: Center for Performance Assessment.
Schmoker, Michael J. (1999). Results: The key to continuous school improvement, 2nd ed. Alexandria, VA.: Association for Supervision and Curriculum Development.

Weick, Karl E. (1995). Sensemaking in organizations. Thousand Oaks, CA.: Sage Publications.

Wenger, Etienne. (1998). Communities of practice: Learning, meaning and identity. New York: Cambridge University Press. Wheatley, Margaret J. (2005). Finding our way: Leadership for an uncertain time. San Francisco: Berrett-Koehler.

Wheelan, Susan A., \& Kesserling, Jan. (2005). Link between faculty group development and elementary student performance on standardized tests. Journal of Educational Research, 98(6), 323-331. 